\title{
MIGRATION AND ECONOMICAL DEVELOPMENT OF SMALL COUNTRIES IN EUROPE
}

\author{
Adžić Sofija \\ University of Novi Sad, Subotica, Serbia
}

The paper analyzes the institutional framework and the implementation of the European concept of sustainable development within migration flows. The key research method is factor analysis which is applied to describe the functioning of institutional and market initiatives in the course of establishing a sustainable development regime that absorbs migration flows. The main obstacles in this regard were: poor construction of today's market, the current public system of economic development regulation and low efficiency in absorption of migrant flows. Small countries will have to turn to macro-and microreforms and policies. The framework of sustainable development requires a new approach in the context of the Agenda 2030 will improve: (1) the socioeconomic climate for productive entrepreneurship and employment growth, (2) development of the innovation system under $3 T$, and (3) development of the economy overall.

Keywords: sustainable development; small countries; migration policy; 3T (Technology, Talent and Tolerance)

\section{Introduction}

Evident changes in small countries, especially in the fields of science, technology, communication, urbanization, economic growth and demography, have not yielded truly adequate results despite all the economic reforms. The once an original idea of establishing a developed community of countries seeking to offer an economic and political counterbalance has turned into fictitious sovereignty that spontaneously destroys all the available potential of

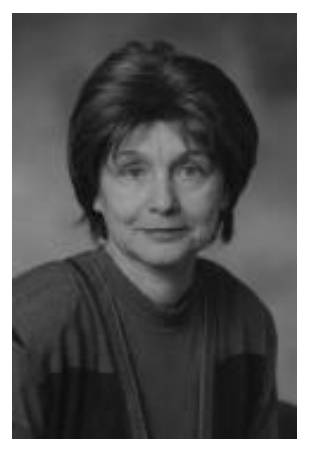

\section{Sofija Adžić}

Full professor at University of Novi Sad, Faculty of Economics in Subotica, Serbia.

Her research interests and subjects include economic system and economic policy, regional economy of the EU, and industrial policy of the EU. She has actively participated on 118 international conferences in Serbia, Bosnia and Herzegovina, Brazil, Bulgaria, Montenegro, Greece, the Netherlands, China, Croatia, India, Italy, Japan, South Africa, Hungary, Macedonia, Malaysia, the Russian Federation, Slovakia, Slovenia, Spain, USA, Thailand and the UK. All of these papers were published in conference preceding, monographs, scientific and professional journals. She has published 9 textbooks, 9 scientific monographs and participated in 55 collective monographs. In addition, she has published 162 scientific papers in national and international journals. She has participated in the development of 26 macroeconomic and 18 microeconomic projects.

E-mail: s.adzic@gmail.com 


\section{MIGRATION AND ECONOMICAL DEVELOPMENT}

small national economies. In-depth analysis of the achieved results does not show the achievement of the set developmental national goals. On the opposite, over the past years, manifestation of the large capital interests was only growing, and it was never in accordance with the development of small countries. This trend has produced various tensions within small countries where citizens are seen mostly as consumers rather than as active business actors, thus, they are doomed to become "passive citizens of social and economic life ... governed by strangers".

This, to some extent, may serve well their individual interests, however, simultaneously destroying the comparative potential of small economies. In the context of such disrupted development, the issue of successful reconstruction of the national space of small countries is now being reconsidered within the framework of economic efficiency. Small countries entered the transition process with rather simplified development strategies based on a simplified model of liberal capitalism in which international synchronization of macroeconomic measures was carried out. Due to this, many developing nations have soon found themselves locked in some sort of vicious cycle.

At the beginning of the current decade, deficit growth in small countries has been shaken off, while high public debt has burst, and unemployment has been reduced thanks to foreign investment inflow and liberal economic migration flows in Europe (Tran Van et al., 2018), as well as the acceptance of many migrants from other continents. The medium-term macroeconomic framework was created in line with the reform flows so that to stimulate the investment activities. Continuous growth in foreign direct investments has significantly increased the efficiency of public infrastructure projects that will be followed in the coming period by stronger domestic investments, primarily from the segment of small and mediumsized enterprises. This will eventually create new opportunities for productive engagement of economic migrants who will contribute to successful sustainable development of small countries (Maltsev et al, 2017).

\section{The General Framework of Economic Policy for New Migration Flows}

In order to achieve greater functional efficiency, small countries must constantly adjust their institutional systems to the European Union's institutional system, though keeping in mind own national and economic sovereignty. The need to implement these adjustments arises from the requirement to change the very economic structure that is supposed to provide much higher economic growth rates in the near future with more intensive production.

In the light of the fourth industrial revolution, in addition to ongoing reform processes, innovative activity must be recognized as an important element in aligning the structure of the economy with the needs of society and contemporary civilizational trends. Reforms of the education system, regional dispersion of foreign direct investments, incentives for employment of young people, as well as other vulnerable categories of society, support to social entrepreneurship, gender-responsive budgeting and re-raising the minimum labor costs are just some of the measures that should provide inclusive and socially equitable distribution of growth which, through the established environment of social cohesion, will result in the labor engagement of all migrants and poverty reduction in small countries.

Creation of a new European "integrated mixed economy" is inseparable from the construction of an economy based on the new production structure within the industry 4.0 and using the innovative flows of converged and related energy, infrastructure and other 
communication systems. Geopolitical repositioning of Europe in the Euro-Asian context is a necessary condition for social security and economic stability according to the principles "without sovereignty -- no socioeconomic development".

Changed geopolitical reality requires the consideration of many complex factors of today's development, which include very pronounced migration flows.

Agenda 2030, with its 17 goals of sustainable development, highlights three key dimensions: economic growth, social inclusion (which means inclusion of migration flows, inter alia) and environmental protection (United Nations, 2015). Realization of these goals should help institutional development and more intensive business cooperation in an adequate business environment for innovative and creative work, fulfilling all working and living conditions under higher standards of living.

The goals of sustainable development under such agenda are:

1. The world without poverty: to end poverty everywhere and in all its forms;

2. A hunger-free world: end hunger, achieve food security and improved nutrition, to promote sustainable agriculture;

3. Good health: to provide healthy life and promote well-being for all generations;

4. Quality education: provide inclusive and quality education and promote lifelong learning opportunities;

5. Gender equality: to achieve gender equality and empower all women and girls;

6. Clean water and sanitation: to provide sanitary conditions and access to drinking water for everyone;

7. Available and renewable energy: to ensure access to affordable, high-tech and sustainable energy for all;

8. Dignified work and economic growth: promote inclusive and sustainable economic growth, employment and decent work for all;

9. Industry, innovation and infrastructure: build adaptive infrastructure, promote sustainable industrialization and foster innovations;

10. Reducing inequality: reducing inequality between and within states;

11. Sustainable cities and communities: To make cities and human settlements inclusive, safe, adaptable and sustainable;

12. Responsible consumption and production: to provide sustainable forms of consumption and production;

13. Climate action: To take urgent actions to combat climate change and its consequences; resources;

14. Life under water: to preserve and sustainably use oceans, seas and marine

15. Life on the Earth: To manage forests sustainable, combat desertification, stop and reverse land degradation and prevent the destruction of biodiversity;

16. Peace, justice and strong institutions: Promoting peaceful and inclusive societies for sustainable development, ensuring access to justice for all and building effective, reliable and inclusive institutions at all levels;

17. Partnership to the goal: to consolidate global partnership for sustainable development.

Since 2010, sustainable development has been embedded in the Europe 2020 strategy and is based on three pillars: "smart growth" with a focus on education and innovation; "sustainable growth" with a focus on functional realistic production with an impact on the 


\section{MIGRATION AND ECONOMICAL DEVELOPMENT}

environment and "inclusive growth" through job creation and poverty reduction. Thus, today, through the functioning of the European Commission, the European Union provides an overview on the goals and principles of sustainable development of the UN Agenda 2030 and how they will be implemented with the selected priorities.

The EU integration process should be implemented through setting the development priorities in line with the new framework of sustainable development goals - the Agenda 2030. Structural reforms in many small European countries are successful in their very different effects that negatively impact labor market indicators. At the same time, these reforms have also fueled the growth of poverty and caused general decline in living standards. Challenges of policies for social inclusion for vulnerable groups, such as displaced persons, persons with disabilities and Roma, are evident. In our view, the most success was achieved in the following areas: improving access to healthcare, covering children with preschool education, especially in rural areas, establishing a lifelong learning approach, youth unemployment, migration, environmental issues and disaster risk reduction (Bogdanovic, 2007). Most of these topics are, in this or that way, embedded in the 17 goals of sustainable development of 2030, with special attention being paid to the following goals and subgoals: promoting strong inclusive and sustainable economic growth and decent work for all (Goal 8 ), poverty reduction (Goal 1), achieving healthy life for all age groups (Goal 3), providing education for all (Goal 4), achieving gender equality (Goal 5), promoting sustainable industrialization (Goal 9), reducing inequalities within and between countries (Goal 10), improving sustainable consumption patterns and production (Goal 12), achievement of peaceful and inclusive societies and the rule of law (Goal 16) and partnership in realization of all these goals (Goal 17).

The Agenda 2030 will inevitably support the development of domestic technology, research and innovation in small developing countries, among other things, ensuring a suitable environment for industrial diversification and creating as much new knowledge as possible with poverty alleviation.

Table 1 - International environment - macroeconomic indicators

(Source: European Commission data, 2018)

\begin{tabular}{|l|c|c|c|c|}
\hline & $\mathbf{2 0 1 7}$ & $\mathbf{2 0 1 8}$ & $\mathbf{2 0 1 9}$ & $\mathbf{2 0 2 0}$ \\
\hline Real growth of gross domestic product, \% & 3.9 & 4 & 3.8 & 3.8 \\
\hline Real GDP growth in the EU, \% & 2.4 & 2.1 & 1.9 & 1.8 \\
\hline Global trade growth, \% & 5.2 & 4.2 & 3.7 & 3.4 \\
\hline Quarterly EURIBOR & -0.3 & -0.3 & -0.2 & 0.2 \\
\hline $\begin{array}{l}\text { Yields on government bonds of the Eurozone } \\
\text { members }\end{array}$ & 0.3 & 0.5 & 0.7 & 0.9 \\
\hline Exchange rate EUR-USD, end of period & 1.13 & 1.18 & 1.15 & 1.15 \\
\hline Prices of food products, annual changes & 0.5 & 3.6 & 2.6 & 1.4 \\
\hline Oil prices, in USD & 48.5 & 63.4 & 70 & 66.5 \\
\hline
\end{tabular}

According to the estimates of the European Commission, the growth of economic activity in the European Union will continue at slightly lower rates than in the previous period. Growth projections for 2019 were revised downwards from the previous year, due to lower contribution of domestic demand and exports, due to weakening global economic 
activity and rising tensions in trade, slower employment growth and increased uncertainty affecting investment.

The growth of economic activity in the coming period will unfold under the conditions of low inflation, with a slightly larger production gap. The projected growth continues to be based on the previously well known sources: growth in domestic demand due to mildly expansionary fiscal policy, favorable financing conditions for both private and public sectors, as well as favorable conditions at the labor market that will absorb a large number of migrants and enable sustainable growth, since private consumption in the past period was the main driver of growth. At the same time, the international environment has caused a lot of negative effects for small economies, see Tab. 1.

It is evident that small countries have made their development in one direction dictated by the potentials of the winners in the Cold War, and at the same time their "development partners" cynically referred to them as "success", and they were in fact given a somewhat colonial status. This means that the West now dominates many of such small countries in intellectual, political and economic terms. At the same time, there are enough historical reasons to forget economic reasons and turn to collective mentality which is linked to the identity of every nation that cannot be lost from sight. Therefore, we must be admit the fact that today's world is cruel to small and underdeveloped countries, which, ideally, must have a much wider zone of security and economic prosperity based on the traditional values of their own.

Since today's many small countries of the European Union are still lacking strategic frameworks for the development of their key sectors, it is necessary to define the goals of their own sustainable development in order to successfully implement them. Defining the strategic framework requires the determination of very precise goals of sustainable development. In Europe they are divided into four groups:

1. Economic growth (goals 8 and 9 above);

2. Development of human resources (goals 1, 2, 3, 4, 5 and 10);

3. Environment and climate (goals 6, 7, 11, 12, 13 and 15);

4. Institutions, finances and cooperation (goals 16 and 17).

Economic development in small countries should take place in accordance with national circumstances. Planned budget deficits in Central and Eastern Europe at the level of $1,7 \%$ of GDP is offset by progressive GDP growth of over $4 \%$ thanks to the growth of the industrial sector, and primarily thanks to recovery of the manufacturing industry, which today is attracting a significant volume of foreign direct investments, thus diversifying production in small countries.

What concerns all small countries is the fact that their production structure is still dominated by products with lower added value. This fact negatively influences their future development as such. Sophisticated production processes still have very small shares in small economies; however, participation of their high-tech industries in GDP is currently increasing and showing a positive correlation with the growing level of economic productivity through diversification, technological improvements and innovations. Eventually, together they will enable the absorption of a large number of highly educated staff from abroad.

The service sector in small countries of Europe accounts for more than 50\% of GDP and is a true backbone of the economy that records steady growth and greatly affects the 


\section{MIGRATION AND ECONOMICAL DEVELOPMENT}

development of the IT sector in particular. Knowledge-based services account for only $26.5 \%$ of GDP in small EU countries, which is insufficient within the Industrial Revolution 4.0.

The SME sector and entrepreneurs play an important role in the economic environment of small countries. Their share reaches over $80 \%$ of the total number of companies, as they employ $70 \%$ of active labor force absorbed from their own labor market and migration flows from other European countries and the world. A major impediment in further development of this sector is limited access to funding sources and insufficient entrepreneurial ability to use EU funds, which are available but unfortunately, remain unused.

The Europe 2020 Strategy for smart, sustainable and inclusive economic growth is a direct answer from the European Union to the goals of sustainable development by 2030. These objectives derive from the ten priorities mentioned in the "European Union Strategic Agendas in times of change" adopted by the European Council, such as support for jobs, growth and investment (priority 1), stronger and more equitable internal market with a strengthened industrial base (priority 4) as well as stronger and more just economic and monetary union - with a focus on social policies and corporate social responsibility (priority 5, European Council, 2014).

These EU principles are reflected in specific programs and investments projects currently being implemented.

Thus, the European Investment Plan plans to mobilize 500 bln EUR by 2020 to invest in the key sectors such as education, healthcare, water, energy, transport and other areas, bearing in mind the far future of the European Union. Consequently, the focus of all these projects is on sustainable energy, circular economy, mitigation of the consequences from climate change and other important topics. The very principle of circular economy is the EU's answer to how to create new jobs that will be filled today by absorbing workers from the migration flows of Europe and other continents.

While the European Science and Innovation Framework "Horizon 2020" is largely focused on increasing the competitiveness of European economy through the development and application of new technologies, in the medium term, it is expected that labor market trends will continue, which will primarily be reflected in a stronger increase in average wages and decreasing unemployment rate (European Commission, 2014a). The intensified work of the inspection services, after the improved labor legislation and the measures taken in the direction of tax-deducting work, will continue to reduce the number of employees in the gray zone and translate them into the contingent of formal employees. These new working conditions, with regard to the rights and insurance of workers, will be improved, and the positive effect will also be reflected in the revenues of small countries. At the end of the medium-term period, the effects of complex reforms in the education system and an adequate response to the needs of the economy are expected while active measures of training, retraining and support to social entrepreneurship will facilitate the availability of jobs to socially vulnerable categories of society and thus additionally ensure the inclusiveness of economic growth. In the same direction, a new increase in the minimum labor cost will also be created, which eventually should be manifested through increased standards of living for all.

The traditional principles of the EU must be gradually transmitted through the processes of accession to such countries as Serbia, Bosnia and Herzegovina, Northern Macedonia and Albania. 
The importance of sectoral public policies for achieving the overall goal of long-term and sustainable economic growth is deeply linked to the fields of education, employment, rule of law, institutional strengthening, science and innovation, and many other segments that are all subjects of the sustainable development goals.

The Europe 2020 Strategy for Smart, Sustainable and Inclusive Economic Growth, as one of the goals, is supposed to involve $20 \mathrm{mln}$ people to work actively to overcome the risk of poverty and social exclusion by 2020 and thus contribute to accelerated development of Europe (European Commission, 2015). In order to achieve this goal, the "European Platform against Poverty" has been based on a series of actions such as undertaking public policy measures, greater and more successful use of the EU funds to support social inclusion, promoting social innovations, working through partnerships and exploiting the potential of social economies, as well as improving coordination between the countries (European Commission, 2014b). All of the above assumes that a lot of efforts and financial resources must be invested.

These principles of the EU are transmitted through the process of accession to the European Union candidate countries. Within a large number of negotiated papers, small countries align their regulations with the EU principles that are key to poverty reduction. These are: Paper 19 (social policy and employment, which are intensified in Europe by employing educated staff in the framework of sound investment policies, aimed at both foreign investors and domestic ones), Paper 2 (free movement of workers, coming via migration flows), Paper 26 (education and culture; education should be based on innovative flows within "Industry 4.0" through new processes of reindustrialization, based on new digitalization flows) and Paper 23 (judiciary and fundamental rights, which will enable the efficient implementation of legal regulations and strengthening institutions for higher efficiency of production processes, which will manifest themselves through increasing standards of living of the entire population).

The issue of poverty reduction is part of important regional initiatives involving small countries. Thus, the "South East Europe Development Strategy by 2020" is based on the same principles as the Europe 2020 strategy, which are smart, sustainable and inclusive growth (Regional Cooperation Council, 2013). Within this initiative, the "Regional Cooperation Council" is implementing a regional project in the area of Roma integration, which emphasizes the importance of sectoral public policies to achieve the overall goal of poverty reduction, which should be based on a multitude of instruments and measures that will be covered from local development funds. "The Employment and Social Policy Reform Program in the EU Accession Process" (ESRP) must be based on key changes in the areas of employment and labor markets, human capital and skills, social inclusion and protection as well as changes in the pension and healthcare systems (Government of R. Serbia, 2016).

The pension system needs to be made effective, which suggests that all retired persons are supposed to have sufficient resources for a decent and comfortable life. The healthcare system should be functional and contribute to improving health, but not only providing huge profits to the pharmaceutical industry. One of the important topics of this document is the unemployment of young people as a vulnerable category. This has become a truly global problem.

The problem of improving human capital today is to improve the elements of demographic, economic and social policies. In the context of this aim realization, it is necessary to point out three important elements. First, under the conditions of obsolete 


\section{MIGRATION AND ECONOMICAL DEVELOPMENT}

industrial capacities and declining economic activity, the key factor of economic development should be the people and their knowledge, especially due to the fact that societies and economies of small countries entered the transition period with the relatively trained but still relatively cheap labor force that possesses significant experience and skills acquired with the partners from developed market economies. However, experience of many small economics has shown that instead of activating these cadres using their potential and creativity, the current policies have caused the deterioration of the general demographic situation, encouraging emigration of the young, educated, most productive and entrepreneurially oriented part of the population due to their inability to put their knowledge and skills into realization of own individual goals regarding life and work (Lopandic, 2017).

Another element in determining the significance of human capital consists of doctrinal and practical issues related to the volume and sources of investment in the development of human capital. Public investment in human capital cannot be and is not a serious factor as it is reducing the developmental propaganda, extorting private initiative and destimulating individual efforts to invest in development and improvement of knowledge and skills.

In the context of active demographic policy, it is necessary to stimulate the increased birth rate so that to move from the phase of depopulation to the phase of at least light growth. However, small countries must not lose sight of the fact that any public intervention in demographic flows is extremely expensive and uncertain, and sometimes may come up with contradictory results. In that sense, active demographic policy must be also cautious and fundamentally based on a detailed and precisely determined professional argumentation without doctrinal prejudices and unconditional conclusions.

An active migration policy applied within new geo-economic flows will contribute to tackling labor market problems that are now only arriving to small countries. Its basic goals must be: reduction of economic migration and selecting the most economical and most rational measures for the engagement of all migrants.

However, one thing is obvious: no form of active demographic policy can be operationalized without renewing the growth of productive employment and activation of labor market functions in the micro-alignment of "human capital". Thus, the direct connection between demographic and economic policies in small countries is currently undermined. The necessary but still insufficient condition for demographic revitalization is realization of a successful economic policy according to the concept of good governance and reforms in the direction of building an efficient labor market, which will be upgraded with effective migration policy on the background of new geopolitical conditions.

If the main function of each market is to increase efficiency in the use of scarce factors in the course of production and economic development, it is obvious that the key function of the labor market is to harmonize the supply and demand and balance the labor price so that to provide optimal allocation of the human capital.

Thus, we come to the need for a closer determination of the content of the third element - the social policy, which should enable the creation of a general social framework for efficient functioning of the labor market. Its contents must be upgraded through economic policy by determining the concept of a good society. This determination should be the result of analyzing the public perceptions of the active role of labor market in small countries. Today, the key visible form of its activity is the continuous growth of unemployment with all the accompanying manifestations of social desperation. The links between a good society, a good government and a successful economic policy are difficult to establish because their 
contents are not unambiguous, nor can they be directly copied from the practices of other countries. Small countries face this major challenge of formulating and implementing the concept of a liberal migration policy for skilled workforce.

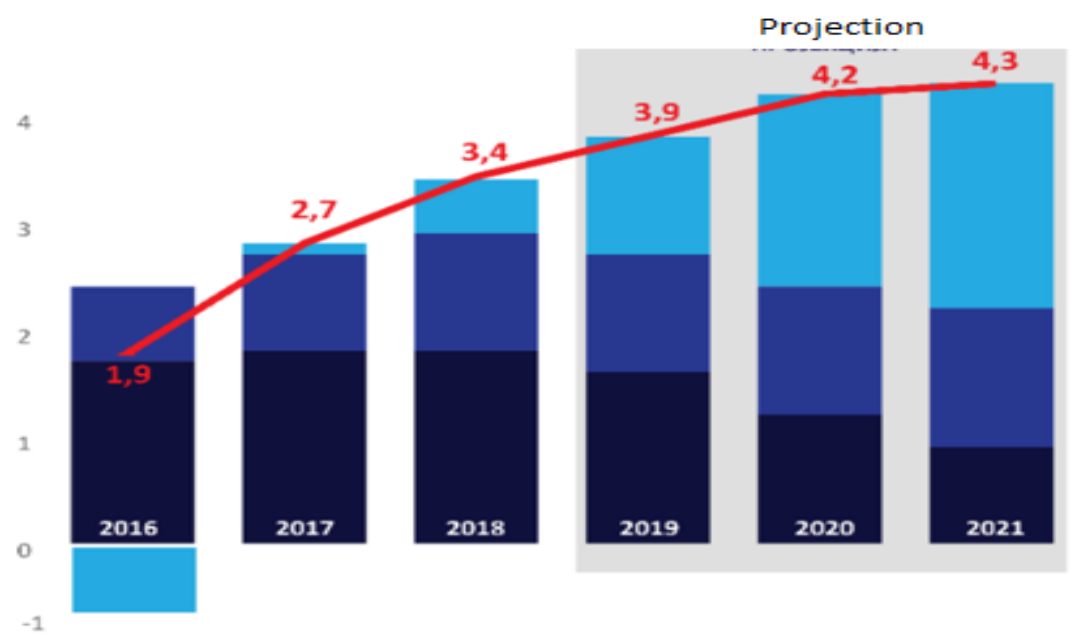

Figure 1- Contribution of production factors to potential growth rates in small EU countries (Source: According to the Eurostat data, as of 2018)

With this growth dynamics (see Fig. 1 above), the production gap will be more pronounced very soon, as the growth of the potential GDP in this period will be determined by the increased inflow of foreign direct investments. Their impact on productivity and efficiency is twofold: through technology transfer and through knowledge transfer. It is also expected that this trend will be strengthened by domestic innovative activities. In addition, the growth of potential GDP will be affected by favorable trends at the labor market, and at the end of the medium-term period, there will be a visible impact of the education reforms undertaken so far through the reduction of structural unemployment. Digitization will greatly accelerate these processes and further increase the efficiency of available capacities' utilization.

The concept of migration flows in the context of sustainable development in small countries must fulfill the several key assumptions:

(1) Target value: Equal rights to access the economic resources, access to basic services, ownership and land management, new technologies and financial services including microfinance. The Strategy for the Development of Education in Small Countries by 2020 recognizes the disproportionately higher dropout due to the reduction of population numbers and new determination of certain groups within population. The most important is the Strategy for Gender Equality within the EU (European Union, 2017), which defines the following strategic goals within the changed gender patterns and the improvement of gender equality culture. The equality of women and men increased with the application of public policies and measures of equal opportunities, by systemically introducing a gender perspective in the adoption, implementation and monitoring of public policies. Among other strategies, it is important to separate the "EU Education Strategy till 2020" which is focused on the principle of equal access to education for all. Therefore, the target value of sustainable development in the context of migration flows should allow free movement of people and capital in search for adequate job that will provide the level of wages necessary for comfortable life after creative and innovative work (European Commission, 2018). 


\section{MIGRATION AND ECONOMICAL DEVELOPMENT}

(2.) Adequate food safety and sustainable agriculture

Agriculture is one of the key branches in the economies of small countries, even though conditions for its development in many of them are extremely unfavorable. There are numerous problems in this sector, which are related to: unfavorable structure of agricultural holdings, technical and technological backwardness, especially among smaller farms, poor organization in cooperatives, insufficiently high level of processing in the existing food industry. More and more often, the consequences of the increasingly severe crises caused by natural factors (floods, droughts etc.) have been enhanced by the professional challenges of farmers facing increasing pressures due to rising standards and regulations in the process of alignment with the EU common agricultural policy. For the development of the agricultural sector and rural development overall, the most important strategic document for small countries would be the "EU Agriculture and Rural Development Strategy" (European Commission, 2014c). This Strategy has identified the following strategic development goals: 1) production growth and stability of producers' income; 2) increasing competitiveness, adapting to the demands of domestic and foreign markets and technical and technological improvement of the agricultural sector; 3) sustainable resource management and environmental protection; 4) improving the quality of life in rural areas and reducing poverty; 5) Efficient management of public policies and improvement of the institutional framework for the development of agricultural and rural areas, which have not been realized because many products are imported today, for example, from the People's Republic of China etc.

(3) Innovative processes within industrialization require the definition of new development directions, which should be linked to the available comparative advantages of each small country and its ability to adaptively change in the course of innovative development. The dilemma is whether small countries are actually ready for the fourth industrial revolution and automation of business and production processes, since they do not have own well-developed strategies, nor enough staff to implement these strategies it. This constant need in high-quality personnel means that the education system must create them continuously. What has been created is already scattered around the world, and the exodus of high-quality cadres still continues, and for that reason, it might be appropriate to consider that very soon already migrants from other countries might be also coming to small countries of Europe.

The thesis about bright technological future for now is only a slogan. It is most certain that small countries should not choose the path of colonial dependence, but should select own innovative directions that will use all available visible and invisible resources for future development of production and non-productive activities with high level of newly created value. Therefore, the economic system of small countries is a way for the society to be organized on the basis of (1) primary factors of production (land, labor, capital), (2) key sociohistorical factors and (3) interconnected active elements: ) form of ownership, (b) types of labor relations, ( c) institutional frameworks in which the economic processes take place, (d) methods of governance, (e) methods of regulating economic trends and (f) business objectives that are usually formulated as follows:

- What to produce?

- How to produce?

- Where to produce? 
- When to produce?

- For whom to produce?

which are derived from the fundamental contradiction of the economic reality that exists between unlimited human needs for goods and services and limited production capacities dictated by the available resources and production factors and today increasingly, by the availability of innovative knowledge and skills.

The problem of "what to produce" is a delicate one for all small countries because it asks for the answers to essential questions: (a) what are the products and in what quantities are they needed to meet the needs of population (b) which types of production are based on the lowest consumption of the available production factors; and (c) which products might have the strongest comparative advantages as compared to other countries, regions and continents.

Answering all these questions might help placing small countries among the most progressive developing countries. Inadequate (at least so far) economic and structural reforms cannot provide an adequate response. Therefore, small countries must apply a very careful and moderate economic diplomacy that will create conditions for rational responses in new geoeconomic conditions. After defining the answer to the "what to produce", the problem of "how to produce" in the context of economic rationality leads small countries to the search for an optimal combination of resources with the lowest costs and the greatest effects at the same time. While finding the answer to the question "where to produce" the answer should be sought in the selection of an optimal territorial organization of production, depending on the understanding of regional differences. Of course, all this should be organized under the innovation concept of "Industry 4.0" and in the context of future development strategies of small countries.

The problem of "when to produce" must be viewed simultaneously in the short, medium and long terms. The problem "for whom to produce» is located between production and distribution, that is, it goes from the ever-increasing appropriation of certain factors of production by the owners.

These problems of "what", "how" and "when to produce" seek answers to the fundamental issue business efficiency that is important for every small country. The questions of "where" and "for whom to produce" should provide answers to the fundamental problem of inequality in every society, which is now very pronounced. The answers to these questions together form the basis for a new development strategy for small countries, which must be based on establishing a development road that will ensure continued expansion of sustainable development opportunities, since the essence of every economic system, even in small countries, is to simultaneously provide greater efficiency and greater equity for all members of society.

(4.) Reducing inequalities between and within countries:

Here belong the topics of growth of lower-income small EU countries, social inclusion, anti-discrimination, and fiscal policy in its connection to local salaries etc. All these topics must be carefully analyzed due to many risky moments. For example, how strict rules can coexist together with creative innovative work? What is the proper salary level for creative innovative work? What levels of knowledge and skills can be treated as appropriate for creative innovative work? and so on.

In this regard, let's have a brief look on the salary situation in the countries in question. The average salary in the small countries of the Balkans is around 402 EUR (Eurostat, 2018). 


\section{MIGRATION AND ECONOMICAL DEVELOPMENT}

The average salary in Montenegro is 510 EUR, in Bosnia and Herzegovina -- 439.71 EUR, Albania -- 427, Croatia -- 813 EUR. The lowest salary in this region is in Macedonia -- 375 EUR. Indeed, inequities in the small countries of the Western Balkans are also the issue of the macroeconomic policy which gives importance to foreign investment with its large donations. The important open question here is whether inequalities between and within countries that do not have the production of final products can be neutralized as such.

Inequality in income distribution is significantly higher than the average value for 28 EU countries and is also higher than the highest recorded in the EU member states. Thus, in 2016, the Gini coefficient for the said countries was 38.6, which is significantly above the average for the 28 Member States of the European Union (30.6), and above the value of the Gini coefficient for the EU countries with the most pronounced inequalities. This situation clearly requires an appropriate response through corresponding policy measures (Arkhipov et al., 2018). The Gini coefficient measured by the distribution of consumption has low value nearly at the bottom of the world's list of Gini coefficients, which means that inequality of consumption in small countries is moderate. It is similar to other indicators of inequality.

Crucial importance for the 2030 Agenda implementation has the goal called "Partnership to Goals" because the scope and ambiance of the Agenda imply the involvement of many partners such as national parliaments, regional and local authorities, academic community, civil society and the private sector to mobilize all available resources necessary to achieve all the goals of sustainable development. In this sense, this goal is more thematically unspecified than the others because it covers the whole spectrum of action fields. It covers target values for finance, technology, exchange, capacity building and very important systemic issues. It relates to domestic budgets, debt management, international business and finance, international development cooperation, international trade, system issues, science, technology, innovation and capacity building, and is finally crucial to the planning of target values.

Promotion and use of innovative technologies has also increased the export of developing countries, and in 2017, the main export products of the countries in question were parts for cars, parts for electric machines, fruits and vegetables, metals and crops, and the like.

The EU Strategy for South Eastern Europe mentions the following Development Pillars: Integrated growth (larger volume of foreign trade and investment at the regional level with three dimensions related to "free trade zone", "competitive economic environment" and "integration into global economy"); Smart growth (with four dimensions: "human resources development","research, development and innovation", "digital society" and "culture and creative sectors"); Sustainable growth (with the dimensions of "resource efficiency" and "competitiveness"); Inclusive growth (includes the dimensions "employment" and "health") and finally, Growth Management, which means increasing the capacity of state administration in establishing the rule of law, curbing corruption and creating the right business environment (Regional Cooperation Council, 2013).

The Action Plan for the Regional Economic Area in the Western Balkans (MAP) stems from thecommitments undertaken within the framework of the Strategy for South-East Europe 2020 and Central-European free trade agreement based on the principles of the Stabilization Agreement and Accession to the EU. The plan contains 4 thematic priorities. The theme "Trade" assumes the adoption of additional protocols under the CEFTA agreement on key services such as finance, insurance and traffic. This includes provisions on 
e-commerce and external customs tariffs. As per investments, an agreement was reached on the establishment of the Regional Investment Plan which should include the exchange of information and best practices in the implementation of investment politics. Mobility refers to removing obstacles to the free flow of skilled labor through recognition of professional qualifications and removal of barriers to mobility of students and researchers in higher education, which must be based on the creation of a business that will absorb economic migrants of Europe and, in particular, the migrants of Asian countries.

In accordance with the 2030 Agenda, the Strategy for the Danube Region include the following interrelated areas: environmental protection, linking and strengthening of the region and building a prosperous society through mobility (all transport modes), sustainable energy, culture and tourism, environmental risks, biodiversity and quality of air and soil, water quality, knowledge society, people and skills, competitiveness, institutional capacities and cooperation, security (European Commission, 2017).

The EU Strategy for the Adriatic-Ionian region consists of 4 pillars: Blue growth (fisheries and aquaculture), environmental quality (transnational habitats and biodiversity), connecting the region (maritime transport, intermodal connections with the hinterland, energy networks) and sustainable tourism (sustainable and responsible tourism management), to which horizontal aspects are applied: capacity building, development and research, small and medium-sized enterprises, climate change and risk management (European Commission, 2014b).

\section{Conclusion}

The key problem of sustainable development and labor markets of the small countries is the fact that in the past twenty years there has been no critical mass of manufacturing entrepreneurs, managers and professional teams capable of tackling the problems and challenges of highly complex reindustrialization and innovative development.

In this context, one could easily draw the conclusion that future development of the small countries will absorb the migration flows from European countries. Therefore, it is necessary to identify all related obstacles and shortcomings and to eliminate them with the newer economic and investment policies. It is crucial that entrepreneurs and managers in cooperation with the state and academia, set up very ambitious goals of the macro-, mesoand business levels to make sure there is a greater share of newly created value per unit and to find new original ways for this.

Small countries today are going through the regression period. Regression is not only economic, but also political, cultural and even civilizational. Hence, the problem of young people leaving these countries and economic migration overall is, first of all, the consequence from the loss of all hopes. Many want to escape from the society they perceive as ill. The states can slow down the departure of these young people by demonstrating the ability to retain labor force and provide permanent support. To begin with, it is necessary to reform all government services and public companies so that they can provide much better services for the entire population. Then, it is necessary to show that in small countries, creative and smart people always have a chance.

Today, from the European, but also from every other angle, small countries resemble colonies, just as many other countries in transition. The most valuable property today is often in foreign hands, and for this very reason, it is not possible to improve general economic 


\section{MIGRATION AND ECONOMICAL DEVELOPMENT}

indicators of these small countries. The current economic model is essentially wrong, but very few politicians and scientists want to recognize this. Small countries are fooling themselves and are now wasting time and energy on the wrong side. The promise of a European future only means that the EU would control even more of political and economic processes in small countries, thus keeping them in a secure geoeconomic dependency.

\section{References:}

Arkhipov, A. \& Ushakov, D. (2018). Functional effectiveness and modern mechanisms for national urban systems globalization: The case of Russia. E-Planning and Collaboration: Concepts, Methodologies, Tools, and Applications, 3.

Bogdanovic, N. (2007). Small rural households in Serbia and rural non-agricultural economy. Belgrade: UNDP.

European Commision, (2014a). Horizon 2020. Retrived on 30.12.2018 from: https://ec.europa.eu/programmes/horizon2020/what-horizon-2020

European Commision, (2014b). European Platform against Poverty. Retrived on 30.12.2018 from:https://ec.europa.eu/programmes/horizon2020/what-horizon-2020

European Commision, (2014c). Rural development 2014-2020. Retrived on 28.12.2018 from: https://ec.europa.eu/agriculture/rural-development-2014-2020_en

European Commision, (2014d). For a prosperous and integrated Adriatic And Ionian region. Available at: from: https://ec.europa.eu/regional_policy/sources/cooperate/adriat_ionian/pdf/brochure_250914.pdf

European Commision, (2015). Europe 2020 strategy. Retrived on 20.12.2018 from: https://ec.europa.eu/info/business-economy-euro/economic-and-fiscal-policy-coordination/eueconomic-governance-monitoring-prevention-correction/europeansemester/framework/europe-2020-strategy_en

European Commision, (2017). EU strategy fort he danube region. Available at: https://ec.europa.eu/regional_policy/sources/cooperate/danube/factsheet_eusdr_en.pdf

European Commision, (2018). European Policy Cooperation (ET2020 framework). Retrived on 30.12.2018 from: https://ec.europa.eu/education/policies/european-policy-cooperation/et2020framework_en

European Council, (2014). Strategic agenda for the union in the times of change. Available at: https://www.consilium.europa.eu/uedocs/cms_data/docs/pressdata/en/ec/143477.pdf

Eurostat (2018). Earnings. Retrived on 15.01.2018 from: https://ec.europa.eu/eurostat/web/labourmarket/earnings

Government of R. Serbia (2016). Employment and Social Reform Programmeinthe Process of Accessionto the European Union. Available at: http://socijalnoukljucivanje.gov.rs/wpcontent/uploads/2016/06/SIPRU-ESRP-2016-English.pdf

Lopandic, D. (2017). European Union and Serbia, New Time and New Environment, Belgrade: The European Movement in Serbia, 47-119.

Maltsev A. A, Mercier-Suissa C, Mordvinova A. (2017), Interpretation of the Term "Reindustrialization" in the Conditions of Globalization. Economy of Region: 1044-1054.

Regional Cooperation Council (2013). Sout East Europe 2020. Available at: https://www.rcc.int/files/user/docs/reports/SEE2020-Strategy.pdf

Tran Van, H., Tran Huu, A., \& Ushakov, D. (2018). Liberal reforms \& economic growth: Current issues and interrelations. Journal of International Studies, 10(4). 
Paper submitted

02 March 2020

Paper accepted for publishing

08 May 2020

Paper published online

O2 June 2020 